\title{
The study of deformations of the soil mass at construction of underground structures with advanced anchoring
}

\author{
Sergey Stradanchenko ${ }^{1}$, Stanislav Maslennikov ${ }^{1 *}$, Vladimir Dmitrienko ${ }^{1}$, Irina Kokunko ${ }^{1}$, \\ and Yuri Chertov ${ }^{1}$ \\ ${ }^{1}$ Institute of service and business (branch) of Don state technical University, 147 Shevchenko, 346500, \\ Rostov region, Shakhty, Russia
}

\begin{abstract}
The development of underground space has a negative impact on the state of objects on the surface. The search of effective ways to prevent deformation of the soil mass has not lost its relevance. The study focuses on advanced anchoring. Based on the analysis of the technological and structural solutions for the construction of the dismantling chamber No. 1 of the Kalininsko-Solntsevskaya line of the Moscow Metro, and studies of stress-strain states of the marginal rock mass in the bottom hole zone by using the finite element method, the measures to ensure the stability of the surrounding rocks and the protective screen of the chamber were considered. The simulation of the stress state of the rock massif shows the weaknesses in the operation of the structures, so the solutions for reducing the surface shrinkage during hardening of the array by advanced anchoring were proposed.
\end{abstract}

\section{Introduction}

Every year, the solution of town-planning problems of large cities becomes complicated due to significant social changes and unfavorable trends in the functioning of urban infrastructure, since the centers of cities are becoming more administrative and commercial. The increasing volumes of public activity in the continuous development of the central areas of cities significantly affect the operation of transport and engineering infrastructures, which requires new approaches to solution of these problems [1-2].

Therefore, in all developed countries of the world, the solution of problems of the development of municipal and residential transport systems in the historical centers of cities is associated with the development of underground space. Moreover, the usage of point underground objects prevailed before, now state programs of integrated development of underground space are being widely implemented. For the construction of shopping and entertainment facilities, parking lots, transport and engineering facilities - it is advisable to create a single network of integrated public spaces with development of both the ground and underground parts of the territories, streets, squares and boulevards, as well as a single

* Corresponding author: maslennikovsa@mail.ru 
network of underground pedestrian connections. This will allow placing the multifunctional underground and aboveground-underground complexes in the most necessary places, freeing the surface of the earth from numerous structures, rooms and devices which are not connected with the permanent presence of people in them, thereby increasing the areas of open, greened and watered spaces for the population [3-6].

The construction of urban underground facilities reducing costs, in most cases, is carried out at shallow depths. But in case, when the long workings are made in alluvial rocks the process is characterized by very difficult conditions. Modern technologies for the safe work of the long workings provide for the use of high-performance systems and special measures to increase the stability of rock outcrops. However, in the construction of auxiliary facilities of small length, the use of such technologies is impossible or it can lead to a significant increase in the cost of work. In this case, excavation is carried out under the protection of temporary support, which is accompanied by a long period of staying rock outcrops without permanent support. The analysis shows that in this case relaxation processes are developed and soil displacement in the bottom hole zone is increased. In most cases, this is accompanied by rock heaps and, accordingly, by a significant increase in displacements above the tunnel.

Therefore, the technological solutions in the design should take into account the displacement of the earth's surface and, accordingly, the deformation of the foundations of the overlying buildings and structures above the tunnel. However, in the conditions of the existing urban development and a number of geotechnical factors, this task is one of the most labor-intensive. Thus, the study of the deformations of soil massifs, to establish the laws of the displacement of the surface during tunneling, became the most relevant research in the construction of underground structures in a megacity [5].

\section{Materials and Methods}

With the increase in the depth of the tunnel, there is a decrease in the shrinking of rocks in the trough zone, but in the construction of deep-laid tunnels, the development of the trough displacement of the earth's surface can capture entire housing estates. Therefore the most relevant is the search of effective ways of improving the sustainability of the soil mass.

One of these methods, preventing the displacement of a soil massif, is considered to be anchoring of rocks around the tunnel. This can be achieved by drilling wells along the contour of production and injection of a hardening suspension into the well. Drilling wells is carried out in the direction of a moving tunnel at a given angle to its axis [5].

Pumping injection of quick-hardening solution is mixed with the destroyed rock to solidify and prevent deformation displacements in the massif, which is essential for reducing the deformations of the surface at the tunnel construction site [5]. This method has been used in many sites and has proven its effectiveness in mountain massifs with high permeability coefficient; however, in cohesive soils and fine-grained sands, its efficiency is sharply reduced due to the small radius of spreading the solution from the wells.

A very effective way of improving the stability of the soil outcrops is advanced anchoring. For the first time this method was applied in the early 70s of the 20th century in the Federal Republic of Germany. In the future, the method of penetration with a protective screen made of pipes has become quite widespread, especially in the case of overcoming zones of tectonic faults, as well as in the construction of urban shallow tunnels when it is necessary to ensure minimal sediment of the earth's surface. The essence of the technology is to strengthen the roof of the vault, to prevent displacement of the soil in front of the face due to the formation of a creeping prism, which can lead to its collapse and deformation of the ground surface. Most often, hardening is carried out by forming a protective screen of steel pipes with a diameter of 100-120 mm, embedded in cement mortar in wells up to $15 \mathrm{~m}$ long.

A large number of structural elements in the face and in the massif leads to a significant 
change in the stress field around the object and, accordingly, complicate the analytical assessment of the stress-strain state (SSS) of the rock mass and support elements.

In recent years, the finite element method [6-10] has become the most widely used for solving geological and mechanical problems. The application of the finite element method (FEM) is especially important in assessing harmful effects of mining in underground construction in megalopolises, where we have to deal with a complex network of underground and surface structures and relatively small movements. Such modeling can be successfully used to substantiate geotechnical monitoring options and interpret its results, to serve as a tool of justifying measures of protect buildings, structures and natural objects from the harmful effects of mining [11-14].

In the FEM, an assessment of the adequacy of the model to a real object was made by monitoring the coincidence of the calculated sedimentation troughs and the sediment trough obtained from field observations. The simulation results showed that the main factors determining the amount of precipitation are: the depth of the tunnel, the type and coefficient of lateral pressure of the soil. Completed studies of computational soil models were based on the theory of plastically hardening space which has proven effectiveness [15].

Thus, for the estimation of the SSS of the array of displacements of the soil in the down hole zone and on the surface, the modeling by the finite element method is used. The most common approach in the practice of calculating and designing building structures is the option of FEM in displacements.

\section{Results}

Analyzing the project "Construction of the Kalininsko-Solntsevskaya line of the Moscow Metro in the area from Victory Park to the station Ramenki ", it can be noted that during the construction of the dismantling chamber No. 1 a technological scheme with a pilot tunnel is used. The opening of the section of the dismantling chamber is carried out by erecting furnel to the contour of the arch of the permanent lining exceeding the longarin height (I-beams) used as temporary supports to the height.

During the development of the face, the temporary fastening of the roof is carried out with anchors with a rod diameter of $25 \mathrm{~mm}$. The detachment of the longarin in the radial direction is carried out by pillars of pipes with a diameter of $159 \mathrm{~mm}$, and in the transverse rasps. Tightening of the vault is done with boards, and the end walls with metal mesh.

In order to improve such a complex, time-consuming and highly unsafe production technology, it is proposed to use advanced anchoring. To assess the effectiveness of the protective screen, studies of the stress-strain state (SSS) of the marginal rock mass in the bottom zone of the dismantling chamber No. 1 in the area from Victory Park to the station Ramenki are carried out. The dismantling chamber of $22.5 \mathrm{~m}$ long, $12.6 \mathrm{~m}$ wide, $9.6 \mathrm{~m}$ high is passed with a pilot tunnel. The pattern of operation of the anchors of the protective screen in the roof of the chamber can be represented as a multi-span beam resting on the temporary support frames and the ground. However, during excavation, a deformation zone is formed in front of the face, that is, the down hole part of the anchors will be in the prism of creeping. In this case, the maximum bending moment of the multi-span continuous beam with the console takes place on the last support, that is, on the temporary support frame.

Since the steel pipe in the anchor will always be located in the lower zone of the "pressed body", then with the console scheme of the anchor is extremely low, since the cement stone in the upper zone of the "crimp" will not resist tension. That is, even with a small depth of working out, the bending moment will exceed the moment of resistance of the anchor pipe with a console length of just over two meters. Consequently, the anchors of the protective screen, having an insufficient moment of resistance, do not prevent the transfer of pressure from the overlying rocks to the ground in the zone of the sliding prism and, accordingly, to 
the bottom. Therefore, a thorough study of this process is required.

The deformation scheme (Fig. 1) obtained as a result of modeling indicates significant displacements of the face and surface up to $110 \mathrm{~mm}$. Analyzing the distribution of displacements in the down hole zone (Fig. 2), it can be noted that the console part of the anchors is located in the zone of the sliding prism and can be deformed along with the massif due to insufficient bearing capacity in the support zone.

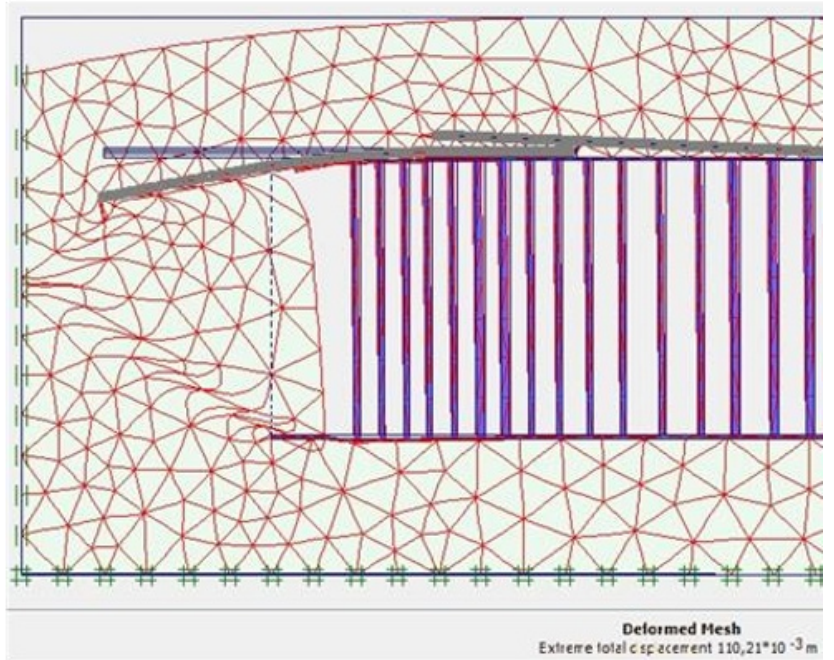

Fig. 1. The deformation scheme of the protective screen anchors

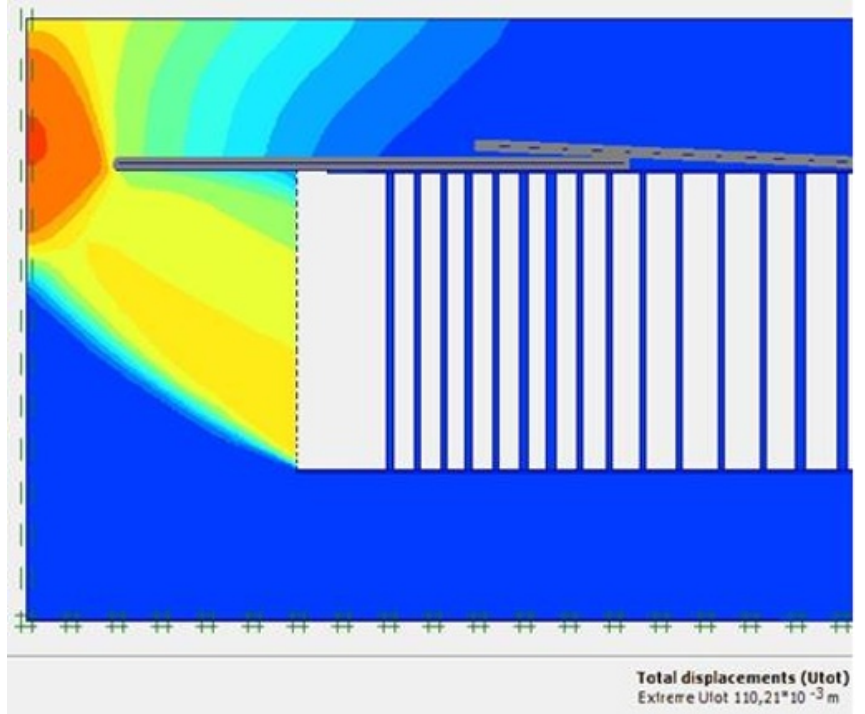

Fig.2. The distribution of displacements in the down hole zone

To reduce the reference point in the anchors of the arch is possible by changing the scheme of their work with increasing length. In this case, the down hole part of the anchors will rest on the ground outside the creeping prism (Fig. 3). This can significantly reduce the 
deformation of the anchors of the protective screen and, accordingly, the surface draft to 6.8 $\mathrm{mm}$, that is, more than an order of magnitude. According to the simulation results, zones of stress concentration and displacement, which are located in the lower part of the face, were established (Fig. 4). In this case, to prevent displacement, it is sufficient to install five polymer cement anchors with removable support elements located in the bottom of the most loaded bottom hole zone at an angle of $15-20^{\circ}$ to the longitudinal axis of the chamber. This will increase the compressive force of the soil on the lock anchor and reduce the amount of displacement of the face and the surface.

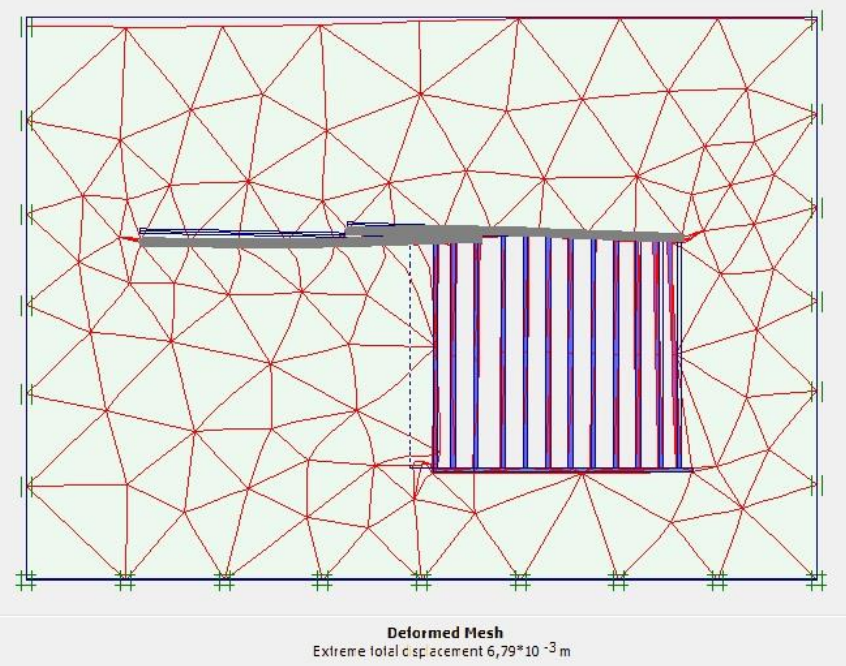

Fig. 3. The deformation scheme of the long shield anchors

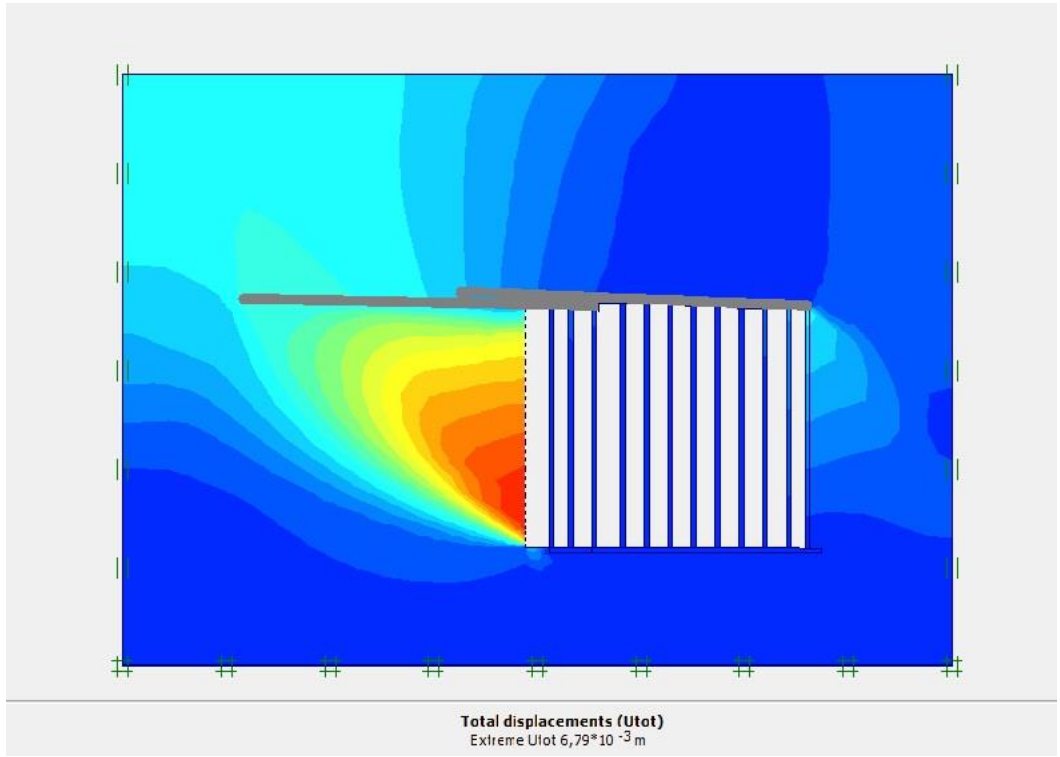

Fig. 4. The distribution of the zones of displacement at the camera bottom 


\section{Conclusion}

To obtain reliable quantitative values of stresses and displacements, a number of influencing factors should be taken into consideration. However, even at this stage of the research, according to the simulation results, it has been established that with a decrease in the emission of the protective screen of less than $9 \mathrm{~m}$, the displacement of the face and the surface is sharply increased. That is, if the length of the anchors is $24 \mathrm{~m}$, the length of the penetration area within one screen entry should not exceed $15 \mathrm{~m}$. This means that for safe passage of the demounting chamber, two safety screen protections must be erected.

Thus, the FEM modeling shows the feasibility of using advanced anchoring to increase the stability of rock outcrops, which will significantly reduce labor, financial and material costs, as well as ensure safe working conditions.

The research was carried out in the framework of the state task 7.9213.2017 / BCh "Development of methods and means of construction and maintenance of underground and deep structures".

\section{References}

1. V.I. Telichenko, M.G. Zercalov, D.S. Konyuhov, Vestnik MGSU. 4. 24-36 (2010)

2. V. L. Belyaev. Vestnik MGSU. 1. 35-46 (2013)

3. V.G. Lerner, E.V. Petrenko, Sistematizaciya i sovershenstvovanie tekhnologij stroitelstva podzemnyh obektov. (Moscow, TIMR, 1999)

4. Z.G. Ter-Martirosyan, Z.G. Ter-Martirosyan, Zhilishchnoe stroitelstvo. 9. 2-5 (2013)

5. A.M. Pavlenko, Gornyy informatsionno-analiticheskiy byulleten 9, 170-173 (2008)

6. R.D. Cook, D.S. Malcus, M.E. Plecha, Concept and applications of finite element analylis. 3 ed. (University of Wisconsin-Madison, 1989)

7. A.Yu. Prokopov, V.F. Akopyan, K.N. Gaptlislamova, Inzhenernyy vestnik Dona 4.

8. O. Rahmani, S. Kebdani, Introduction a la metode des elements finis pour les ingeneurs. (O.P.U, Alger, 1981)

9. N. Chernysheva, L. Rozin, MATEC Web of Conferences, 53, (2016) doi.org/10.1051/matecconf/20165301042

10. URL: http://www.plaxis.nl

11. T. Zommer, S. Chernyshov, MATEC Web of Conferences, 86, doi.org/10.1051/matecconf/20168603011 (2016)

12. S.C. Moller, Tunnel induced settlements and forces in linings (Mit teilungen des Instituts fur Geotechnik Universitat Stuttgart, 2006)

13. E.M. Volohov, S.Yu. Novozhenin, V.I. Kireeva, Markshejderiya i nedropolzovanie. 2. 13-17 (2015)

14. E.M. Volohov, S.N. Zelencov, V.I. Kireeva, Perspektivy razvitiya inzhenernyh izyskanij v stroitelstve v Rossijskoj Federacii: Proc. XI Conf. 90-92 (2015)

15. L.A. Strokova, Izvestiya Tomskogo politekhnicheskogo universiteta. 312. 1, 45-50 (2008) 